Letter for Nature Climate Change

Title page - authors \& affiliations

\title{
Rapid change in East Antarctic terrestrial vegetation in response
}

\section{to regional drying}

Sharon A. Robinson, ${ }^{1,2 *+}$ Diana H. King, ${ }^{1}$ Jessica Bramley-Alves, ${ }^{1}$ Melinda J. Waterman, ${ }^{1}$

Michael B. Ashcroft, ${ }^{1}$ Jane Wasley, ${ }^{1,3}$ Johanna D. Turnbull, ${ }^{1}$ Rebecca E. Miller, ${ }^{1,4}$ Ellen

Ryan-Colton, ${ }^{1,5}$ Taylor Benny, ${ }^{1}$ Kathryn Mullany, ${ }^{1}$ Laurence J. Clarke, ${ }^{1,3,6}$ Linda A. Barry, ${ }^{7}$

Quan $\mathrm{Hua}^{7}$

${ }^{1}$ Centre for Sustainable Ecosystem Solutions, School of Biological Sciences, University of

Wollongong, Northfields Avenue, Wollongong, NSW 2522, Australia

${ }^{2}$ Global Challenges Program, University of Wollongong, Northfields Avenue, Wollongong, NSW

2522, Australia

${ }^{3}$ Current address, Antarctic Conservation and Management Program, Australian Antarctic Division,

Kingston, TAS 7050, Australia

${ }^{4}$ Current address, School of Ecosystem and Forest Sciences, University of Melbourne, Richmond,

VIC 3121, Australia

${ }^{5}$ Current address, Research Institute for the Environment and Livelihoods, Charles Darwin University,

Alice Springs 0870, NT, Australia

${ }^{6}$ Current address, Antarctic Climate and Ecosystems Cooperative Research Centre, University of

Tasmania, Private Bag 80, Hobart, Tasmania 7001, Australia

${ }^{7}$ Australian Nuclear Science and Technology Organisation (ANSTO), Locked Bag 2001, Kirrawee

DC, NSW 2232, Australia

*Corresponding author

${ }^{+}$SAR, DHK, JBA, MJW, MBA and JW contributed equally. 
East Antarctica has shown little evidence of warming to date ${ }^{1-3}$ with no coherent picture of how climate change is affecting vegetation ${ }^{4-6}$. In stark contrast, the Antarctic Peninsula experienced some of the most rapid warming on the planet at the end of the last century ${ }^{2,3,7,8}$ causing changes to growth and distribution of plants ${ }^{9-11}$. Here we show that vegetation in the Windmill Islands, East Antarctica is changing rapidly in response to a drying climate. This drying trend is evident across the region, demonstrated by changes in isotopic signatures measured along moss shoots ${ }^{12,13}$, moss community composition and declining health, as well as long-term observations of lake salinity ${ }^{14}$ and weather. The regional drying is possibly due to the more positive Southern Annular Mode (SAM) in recent decades. The more positive SAM is a consequence of Antarctic ozone depletion and increased greenhouse gases, and causes strong westerly winds to circulate closer to the continent, maintaining colder temperatures in East Antarctica despite the increasing global average ${ }^{15-18}$. Colder summers in this region likely result in reduced snow melt and increased aridity. We demonstrate that rapid vegetation change is occurring in East Antarctica and that its mosses provide potentially important proxies for monitoring coastal climate change.

Climate change is causing many species to shift poleward in response to increasing global temperatures ${ }^{19}$. Antarctic continental vegetation, however, is unlikely to exhibit such simple and predictable responses, as warming is inconsistent over the continent ${ }^{1,3}$, and species distributions are largely determined by local availability of ice-free habitats and water, rather than temperature per $s e^{6,20-22}$. Small changes in microclimate (temperature, precipitation, wind or humidity) can impact the water balance or freeze-thaw cycles ${ }^{23}$ and thus impact vegetation, even in the absence of regional warming. 
Continental Antarctic flora is mainly restricted to ice-free coastal regions and dominated by lichens and mosses, with two vascular plant species found only on the comparatively mild Antarctic Peninsula ${ }^{20}$. We have been monitoring health and biodiversity in well-developed moss communities in East Antarctica (Fig. $1 ;{ }^{24}$ ). Such moss beds occur only where summer ice melt produces temporary streams and lakes, sustaining a short (8-16 week) season of plant growth ${ }^{4,24,25}$. While lichens are more abundant across Antarctica, they grow extremely slowly making them unsuitable for such monitoring.

Over 13 years (2000-2013) we observed significant changes in species composition within moist moss communities in East Antarctica (Fig. 1). Changes in relative abundance of moss species were modelled from microsamples collected from replicate quadrats at sites on two peninsulas in the Windmill Islands [Antarctic Specially Protected Area (ASPA) 135 (A2) and Robinson Ridge (RR)]. This sampling represents two of the four major moss beds, which occur on three peninsulas in this region (Supplementary Fig. S1). We found that moss communities were dominated by the Antarctic endemic, Schistidium antarctici (Figs $1 \& 2$ ), the most tolerant of submergence and least desiccation-tolerant of the three co-occurring species (see Supplementary Table $\mathrm{S} 1 ;^{21}$ ). The relative abundance of S. antarctici was significantly lower than the baseline (2000) in all years between 2008 and 2013 (mean abundance decline 2000 to 2013; ASPA 135: 93.8\% to 63.0\%; RR: $83.4 \%$ to $55.6 \%$; Fig. 2). Conversely, the abundance of the two desiccation-tolerant, cosmopolitan species, Ceratodon purpureus and Bryum pseudotriquetrum, was generally higher than the 2000 baseline over the same period (Fig. 2, Supplementary Table S1). In particular, C. purpureus was significantly more abundant in 2011-2013 compared to 2000 (mean abundance increase 2000 to 2013 ; ASPA135: $0.7 \%$ to $11.4 \%$; RR $0.9 \%$ to $7.7 \%$; Fig. 2 ) at both sites indicating drier growth conditions ${ }^{24}$. Given this species' aversion to submergence ${ }^{21,23,24}$, it is likely that these 
sites are now experiencing reduced periods of water inundation, allowing C. purpureus propagules to establish (Fig. 1).

This apparent drying was further supported by our assessment of changes in vegetation health over the same period. We used digital image analysis to estimate percent cover of moss based on leaf colour (healthy, green; stressed, red-brown; and moribund, grey-black indicating total loss of photosynthetic pigments). In 2003 all quadrats contained at least $70 \%$ healthy, green moss (Fig. 3); however, by 2008 more than half of this healthy moss had turned redbrown in colour (due to drought and high light or other stressors). Red-brown colouration indicates a shift away from photosynthesis and growth (high chlorophyll, green moss) towards investment in photoprotective pigments in response to physiological stress ${ }^{26}$. Mosses can recover if conditions improve; new healthy moss plants can re-sprout through moribund turf and stressed moss will re-green if photoprotective pigments decline relative to chlorophyll. There was some recovery to healthy moss between 2008 and 2013 (Fig. 3); however, recovery differed between the two sites. At Robinson Ridge, stressed moss increased from 5\% to 50\% between 2003 and 2008, with $30 \%$ of the moss remaining in a stressed state in 2013 whereas at ASPA 135 the 2013 percent covers of healthy $(85 \%)$ and stressed (3\%) moss were similar to 2003 (Fig. 3). It is notable, however, that both the microsamples (Fig. 2) and photographs (Fig. 3) suggested that moribund moss increased during the study period, significantly so at ASPA 135. The increased dominance of the two more desiccation tolerant moss species (C. purpureus and B. pseudotriquetrum) at the expense of the endemic S. antarctici (Fig. 2), and the reduction in moss health (Fig. 3), are all consistent with drier microclimates. Given that it can take weeks for the health or composition of mosses to respond to changing conditions in the field ${ }^{21}$, these changes likely represent differences in seasonal growth conditions rather than the specific weather conditions during sampling. While there are variations in microtopography within quadrats 
due to factors such as frost heave, with stressed and moribund moss more likely to occur on the drier and exposed ridges, there has been no consistent change in the microtopography that would explain a directional shift. The changes in moss health and species composition likely reflect moist microhabitats contracting to lower elevations, both within quadrats and across sites.

The trend towards drier conditions in the Windmill Islands is also evident in stable carbon isotope $\left(\delta^{13} \mathrm{C}\right)$ signatures along slow-growing moss shoots of all three species collected from six sample locations including both quadrat sites (A2 and RR, Fig. 4, Supplementary Fig. S1). Antarctic mosses have very slow growth rates and their cellular $\delta^{13} \mathrm{C}$ signatures have been shown to accurately reflect bio-available water ${ }^{13}$. Shoot segments with higher (less negative) $\delta^{13} \mathrm{C}$ reveal periods when moss was growing under wetter conditions ${ }^{13}$ (more submergence; see Fig. 1). Changes in $\delta^{13} \mathrm{C}$ along moss shoots, which can be precisely dated using 'bomb-peak' radiocarbon dating ${ }^{10,12}$ (see Methods), enable interpretation of highlyresolved temporal trends in water availability in Antarctica.

Windmill Islands moss beds support live shoots, up to $135 \mathrm{~mm}$ long, that have been growing for decades ${ }^{12,13}$ at an average rate of $1.4 \mathrm{~mm} \mathrm{yr}^{-1}$ (SD 0.8; Supplementary Fig. S2). Trends in $\delta^{13} \mathrm{C}$ in moss shoots also indicate that bio-available water has declined in the Windmill Islands region since the 1960 s, independent of species or site. On average, $\delta^{13} \mathrm{C}$ decreased at a rate of $0.039 \% \mathrm{yr}^{-1}(\mathrm{SD} 0.068, \mathrm{n}=18)$, and this drying trend was significant in $40 \%$ of these slow-growing shoots (Fig. 4). Variation in $\delta^{13} \mathrm{C}$ trends between shoots suggests localised topography results in some moss shoots drying faster than others, with mosses likely to persist longer in moister microrefugia ${ }^{20}$. That an overall negative $\delta^{13} \mathrm{C}$ trend was found provides further support for a drying trend in this biologically important polar region. 
This regional drying is possibly due to reductions in stratospheric ozone and increases in greenhouse gases causing an intensification in the positive phase of the Southern Annular Mode (SAM; Fig. 5c) ${ }^{15-18,27}$. Ozone depletion since the 1970s has had pronounced effects on Southern Hemisphere climate, most obviously over the spring and summer growing season $\left({ }^{3,16,28}\right.$ and references therein). This has led to increased wind speeds around Antarctica and lower maximum temperatures across much of East Antarctica ${ }^{1,3,16,17}$. Lower temperatures are associated with reduced snowmelt, meaning more water remains frozen and biologically unavailable ${ }^{20}$.

Ozone depletion and the increase in the $\mathrm{SAM}^{3,15,17,18}$ have been linked in recent years to a growing number of biological phenomena across the Southern Hemisphere, including changing growth rates in trees ${ }^{16,29}$ and increased body weight and breeding success in wandering albatross ${ }^{30}$. It seems likely that the Windmill Islands represent another example where regional drying, linked to anthropogenic climate change, is associated with declining plant health and changes to species composition in terrestrial communities, as well as shifts from freshwater species (green algae and cyanobacteria) to diatoms, as nearby lakes become more saline $^{14}$ (see Supplementary Fig. S1 for locations).

To confirm recent changes in regional climate we compiled long-term weather data from the three Australian Government Bureau of Meteorology (BOM) stations (Wilkes, Casey Tunnel and Casey; Supplementary Fig. S1) that have been operational since 1961. Despite interannual variation typical of polar climates, these records are consistent with regional drying in response to the increasing SAM. The number of degree days above freezing per year, a potential indicator of snow melt, decreased by 31\% from 208 (SD 42; 1975-1993) to 143 (SD 44; 1994-2017), largely due to a distinct downward shift in 1993/4 (Fig. 5a, d). Similarly, there has been a trend towards higher mean wind speeds, since $1978(16.3 \mathrm{~km} / \mathrm{h}$ for 1978 1987 to $21.4 \mathrm{~km} / \mathrm{h}$ for $2000-2017$; Fig. 5 b, d). The SAM exhibited a steady increase since 
the 1960s (Fig. 5c), but likely change points in the climate series for SAM, degree days and wind over the 15 years of moss observations (Fig. 5d), suggest that linear trends do not adequately explain recent data. A more positive SAM was significantly correlated with lower degree days, in particular since 1970, when the correlations were consistent for data from the two consecutive Casey weather stations (Fig. 5e; $\mathrm{R}^{2}=0.66, P<0.001$ and $\mathrm{R}^{2}=0.38, P<0.001$ ). Although we found no correlation between SAM and mean wind speeds (Fig. 5f), there is published evidence for such a link ${ }^{16-17}$. While lower snowmelt and higher winds are plausible explanations for drier conditions in moss beds, actual water availability will be determined by a complex balance of snowfall, redistribution by wind, and subsequent melt and refreezing. Unfortunately, precipitation observations are unreliable given the strong winds and blown snow. Therefore, while BOM data supports the drying trend, the evidence is not as strong as the changes in community composition and isotopes, which provide a direct measure of changes in the overall water balance.

In addition to the long-term drying trend apparent in these communities, our results show a sudden decline in plant health occurred in 2008 (Figs 1 \& 3), followed by partial recovery. This could indicate an extreme weather event occurred in that season. BOM synoptic records show lower maximum temperatures and degree days in 2008 (Fig. 5a), but there was also an unusual occurrence of freezing rain, which happens when supercooled raindrops fall in liquid phase but freeze when impacting the surface. Over the 25 years from 1989 to 2014 there were only 16 observations of freezing rain. Twelve of those occurred between 2006 and 2009 with three in December 2007 shortly before the quadrats were monitored in January 2008. Although this evidence is circumstantial, it is plausible that an unusual occurrence of freezing rain caused additional stress to the mosses, and given that disturbance can promote community change ${ }^{31}$, this extreme event may have facilitated the establishment or increase of C. purpureus under this drying regional climate. 
The presence of lichen encroachment over moribund moss has previously been considered evidence for drying conditions in the Windmill Islands; however, the timeframe for this change was unclear ${ }^{24,25}$. It could represent a slow process that has been occurring over the past 2-9,000 years as deglaciation and isostatic uplift have gradually resulted in drier sites ${ }^{24}$; however, evidence is now accumulating that a more contemporary drying trend may also be impacting the region. Rapid increases in salinity from three Windmill Islands lakes suggest drying across the region in recent decades ${ }^{14}$, and a time series of photos from Mossel Lake $\sim 1400 \mathrm{~km}$ away in the Vestfold Hills also provides circumstantial evidence that the drying could be more widespread (Supplementary Fig. S3). Together, the combination of lake salinity records, shoot stable isotope analysis, meteorological data and vegetation monitoring paint a clear picture of recent drying across this region leading to community change.

Our findings suggest a drying trend is affecting East Antarctic terrestrial biota and this work is the first documented case of such change for the Antarctic continent. Antarctic mosses are small and grow very slowly, but their tissues maintain a record of the environmental conditions during growth ${ }^{10}$. The suite of methods applied here demonstrates that Antarctic moss communities are far more responsive to their microclimate than we might predict based on their slow growth rates; indeed we show that rapid changes can and do occur in these terrestrial Antarctic vegetation communities.

The ice-free habitats of the Windmill Islands are amongst the most extensively vegetated areas on the Antarctic continent, with several large moss beds and even larger areas dominated by lichens ${ }^{24,25}$, rendering the area critical for Antarctic biodiversity. Our data suggest that climate change and ozone depletion are already impacting old-growth moss beds in East Antarctica with other, as yet unmeasured, components of Antarctic biodiversity potentially also affected ${ }^{31}$. Continued monitoring of these study areas is important to fully understand the impacts on all terrestrial biodiversity and develop appropriate conservation 
strategies. This is particularly true for the Windmill Islands, as it is the only region of East Antarctica predicted to show an increase in the number of ice-free areas by $2100^{22}$, as a result of a modelled increase in degree days of a similar magnitude to the decrease we report here. Furthermore, given the spatial and temporal paucity of meteorological records for Antarctica, moss communities are important and sensitive biological proxies for tracking coastal climate change around the continent.

\section{Methods}

Methods, including statements of data availability and any associated references, are available in the online version of this paper.

\section{References}

1 Doran, P. T. et al. Antarctic climate cooling and terrestrial ecosystem response. Nature 415, 517-520 (2002).

2 Convey, P. et al. Antarctic climate change and the environment. Antarct. Sci. 21, 541563 (2009).

3 Turner, J. et al. Antarctic climate change and the environment: An update. Polar Rec. 50, 237-259 (2014).

4 Robinson, S. A., Wasley, J. \& Tobin, A. K. Living on the edge - Plants and global change in continental and maritime Antarctica. Glob. Change Biol. 9, 1681-1717 (2003).

5 Guglielmin, M., Fratte, M. D. \& Cannone, N. Permafrost warming and vegetation changes in continental Antarctica. Environ. Res. Lett. 9, 045001 (2014).

6 Brabyn, L. et al. Quantified vegetation change over 42 years at Cape Hallett, East Antarctica. Antarct. Sci. 18, 561-512 (2006).

7 Turner, J. et al. Absence of 21st century warming on Antarctic Peninsula consistent with natural variability. Nature 535, 411-415 (2016).

8 Bromwich, D. H. et al. Central West Antarctica among the most rapidly warming regions on Earth. Nature Geosci 6, 139-145 (2013). 
9 Parnikoza, I. et al. Current status of the Antarctic herb tundra formation in the Central Argentine Islands. Glob. Change Biol. 15, 1685-1693 (2009).

10 Amesbury, M. J. et al. Widespread biological response to rapid warming on the Antarctic Peninsula. Curr. Biol. 27, 1616-1622 e1612 (2017).

11 Hill, P. W. et al. Vascular plant success in a warming Antarctic may be due to efficient nitrogen acquisition. Nat. Clim. Change 1, 50-53 (2011).

12 Clarke, L. J., Robinson, S. A., Hua, Q., Ayre, D. J. \& Fink, D. Radiocarbon bomb spike reveals biological effects of Antarctic climate change. Glob. Change Biol. 18, 301-310 (2012).

13 Bramley-Alves, J., Wanek, W., French, K. \& Robinson, S. A. Moss $\delta^{13}$ C: an accurate proxy for past water environments in polar regions. Glob. Change Biol. 21, 24542464 (2015).

14 Hodgson, D. A. et al. Recent rapid salinity rise in three East Antarctic lakes. $J$. Paleolimnol. 36, 385-406 (2006).

15 Marshall, G. J. Trends in the southern annular mode from observations and reanalyses. J. Climate 16, 4134-4143 (2003).

16 Robinson, S. A. \& Erickson, D. J. Not just about sunburn - the ozone hole's profound effect on climate has significant implications for Southern Hemisphere ecosystems. Glob. Change Biol. 21, 515-527 (2015).

17 Marshall, G. J. \& Thompson, D. W. J. The signatures of large-scale patterns of atmospheric variability in Antarctic surface temperatures. J. Geophys. Res.-Atmos. 121, 3276-3289 (2016).

18 Abram, N. J. et al. Evolution of the Southern Annular Mode during the past millennium. Nat. Clim. Change 4, 564-569 (2014).

19 Pecl, G. T. et al. Biodiversity redistribution under climate change: Impacts on ecosystems and human well-being. Science 355, eaai9214 (2017).

20 Convey, P. et al. The spatial structure of Antarctic biodiversity. Ecol. Monogr. 84, 203-244 (2014).

21 Wasley, J., Robinson, S. A., Lovelock, C. E. \& Popp, M. Some like it wet - Biological characteristics underpinning tolerance of extreme water stress events in Antarctic bryophytes. Funct. Plant Biol. 33, 443-455 (2006).

22 Lee, J. R. et al. Climate change drives expansion of Antarctic ice-free habitat. Nature 547, 49-54 (2017). 
23 Lenné, T., Bryant, G., Hocart, C. H., Huang, C. X. \& Ball, M. C. Freeze avoidance: a dehydrating moss gathers no ice. Plant Cell Environ. 33, 1731-1741 (2010).

24 Wasley, J. et al. Bryophyte species composition over moisture gradients in the Windmill Islands, East Antarctica: Development of a baseline for monitoring climate change impacts. Biodiversity 13, 257-264 (2012).

25 Melick, D. \& Seppelt, R. Vegetation patterns in relation to climatic and endogenous changes in Wilkes Land, continental Antarctica. J. Ecol. 85, 43-56 (1997).

26 Malenovský, Z., Turnbull, J. D., Lucieer, A. \& Robinson, S. A. Antarctic moss stress assessment based on chlorophyll content and leaf density retrieved from imaging spectroscopy data. New Phyt. 208, 608-624 (2015).

27 Williamson, C. E. et al. Solar ultraviolet radiation in a changing climate. Nat. Clim. Change 4, 434-441 (2014).

28 WMO. Assessment for decision-makers: Scientific assessment of ozone depletion. Report No. 56, (World Meteorological Organization, Global Ozone Research and Monitoring Project, Geneva, Switzerland, 2014).

29 Villalba, R. et al. Unusual Southern Hemisphere tree growth patterns induced by changes in the Southern Annular Mode. Nature Geosci 5, 793-798 (2012).

30 Weimerskirch, H., Louzao, M., De Grissac, S. \& Delord, K. Changes in wind pattern alter albatross distribution and life-history traits. Science 335, 211-214 (2012).

31 Gooseff, M. N. et al. Decadal ecosystem response to an anomalous melt season in a polar desert in Antarctica. Nat. Ecol. Evol. 1, 1334-1338 (2017).

\section{Corresponding author}

Correspondence and requests for materials should be addressed to SAR.

\section{Acknowledgements}

The authors wish to thank Dana Bergstrom, Zbyněk Malenovský, Anna Nydahl, Jodie Dunn, Arko Lucieer and other ANARE expeditioners for assistance in the field, Andrew Netherwood for production of Figure 1 and Ben Raymond, Andrew Constable and two anonymous referees for providing feedback on the manuscript. 
Funding was provided by Australian Research Council DP110101714, DP180100113, Antarctic Science Grants 1313, 3129, 3042 and 4046, and Australian Institute of Nuclear Science and Engineering (AINSE) grants 05142P and 06155. We acknowledge financial support from the Australian Government for the Centre for Accelerator Science at ANSTO through the National Collaborative Research Infrastructure Strategy and the University of Wollongong's Global Challenges Program as part of the Sustaining Coastal and Marine Zones challenge. JW, LJC, JBA, MJW and DHK were supported by Australian Postgraduate Awards/Research Training Program Scholarships. MJW also received an AINSE postgraduate award.

\section{Author contributions}

SAR, DHK, JBA, MJW, JW, JDT, ERC and LJC conceived the experiments; JBA, JW, JDT, SAR, REM, ERC and LJC performed fieldwork; DHK performed image analysis; DHK, JBA, JW, JDT, TB and KM processed moss microsamples; MJW, JBA, LJC, LB and QH performed dating and isotope analysis; MBA, DHK, MJW, JBA and QH analysed data; SAR, MBA, MJW, DHK, JBA, JW, JDT, REM and QH co-wrote the manuscript.

\section{Competing financial interests statement}

The authors declare no competing financial interests

\section{Additional information}

Supplementary Tables and Figures are available in the online version of the paper. Reprints and permissions information is available online at www.nature.com/reprints.

\section{Figure legends}


Figure 1 | Changes in East Antarctic moss communities (1982 and 2013). Periodic flooding of moss beds (1982-2000) favoured Schistidium antarctici and Bryum pseudotriquetrum that tolerate submergence (Supplementary Table $\mathrm{S}^{24}$ ); however, Ceratodon purpureus, which does not survive extended submergence, was restricted to higher elevations. The APSA 135 site (photographed in 1999) illustrates inundation and since then the moss beds have dried and experience less submergence. Ceratodon purpureus can now survive and is more abundant, along with increased moribund moss (Fig. 2). Acute stress causes moss colour change (2008) due to more photoprotective (red-brown) pigments with some recent recovery (2013; Fig. 3).

Figure 2 | Community composition at two sites (ASPA 135 and Robinson Ridge), Windmill Islands, East Antarctica, sampled in six summer seasons between 2000 and 2013. The moss community consists of varying proportions of three species and unidentifiable moribund moss (lacking cell contents and essentially dead). Relative abundance $( \pm 95 \% \mathrm{CI})$ was estimated using a Bayesian model based on nine microsamples per quadrat ( $n=10$ quadrats in all years except 2000 where $n=7$; see Methods). The model also estimated the differences in relative abundance from the 2000 baseline year, with asterisks marking significant changes $(* \mathrm{P}<0.05, * * \mathrm{P}<0.01, * * * \mathrm{P}<0.001)$.

Figure 3 | Change in moss health between 2003 and 2013 at two East Antarctic sites.

Photographs demonstrate how moss health changed in a typical quadrat. Graphs show percent cover of three moss health categories (healthy, green; stressed, red-brown; moribund, greyblack). Data are mean percent cover ( $\pm 95 \% \mathrm{CI} ; \mathrm{n}=10$ quadrats per site). Letters denote significant differences $(\mathrm{P}<0.05)$ within health categories. N.B. moss cover categories do not sum to $100 \%$, as quadrats contain small proportions of rock, snow, ice, water and lichens (data not shown), which did not change significantly throughout the decade at either site. 
Figure 4 | Rate of change in moisture availability in East Antarctic mosses since 1960, estimated using isotopic analysis of 18 long moss shoot cores from six sites. Data represent linear trends in $\delta^{13} \mathrm{C}( \pm 95 \% \mathrm{CI})$. Negative $\delta^{13} \mathrm{C}$ change rates indicate that water availability has declined, with significant differences indicated by asterisks $(* \mathrm{P}<0.05 ; * * \mathrm{P}<0.01$, *** $\mathrm{P}<0.001)$. Squares indicate slow-growing cores with less than ten samples available since 1960. Triangles indicate fast-growing cores that span less than 20 years. Quadratic responses were also fitted, but only the three cores marked with blue curves were significantly nonlinear.

Figure 5 | Summer (Dec-Feb) Southern Annular Mode (SAM) and meteorological observations for the Windmill Islands since 1961. Trends in time series (a-c) and the probability of change points (d) were estimated by a Bayesian model (see Methods). Degree days (a, e), an indicator of snow melt, calculated as the sum of maximum temperatures for days when temperatures exceeded $0{ }^{\circ} \mathrm{C}$. Linear regressions $(\mathbf{e}, \mathbf{f})$ determined if SAM had significant relationships with meteorological variables, independent of location. Solid and dashed lines (e) indicate significant trends ( $* \mathrm{P}<0.05$; ** $\mathrm{P}<0.01$, *** $\mathrm{P}<0.001)$, but the slope for Wilkes is different. Dotted lines were not significant (n.s.). 


\section{Figures}
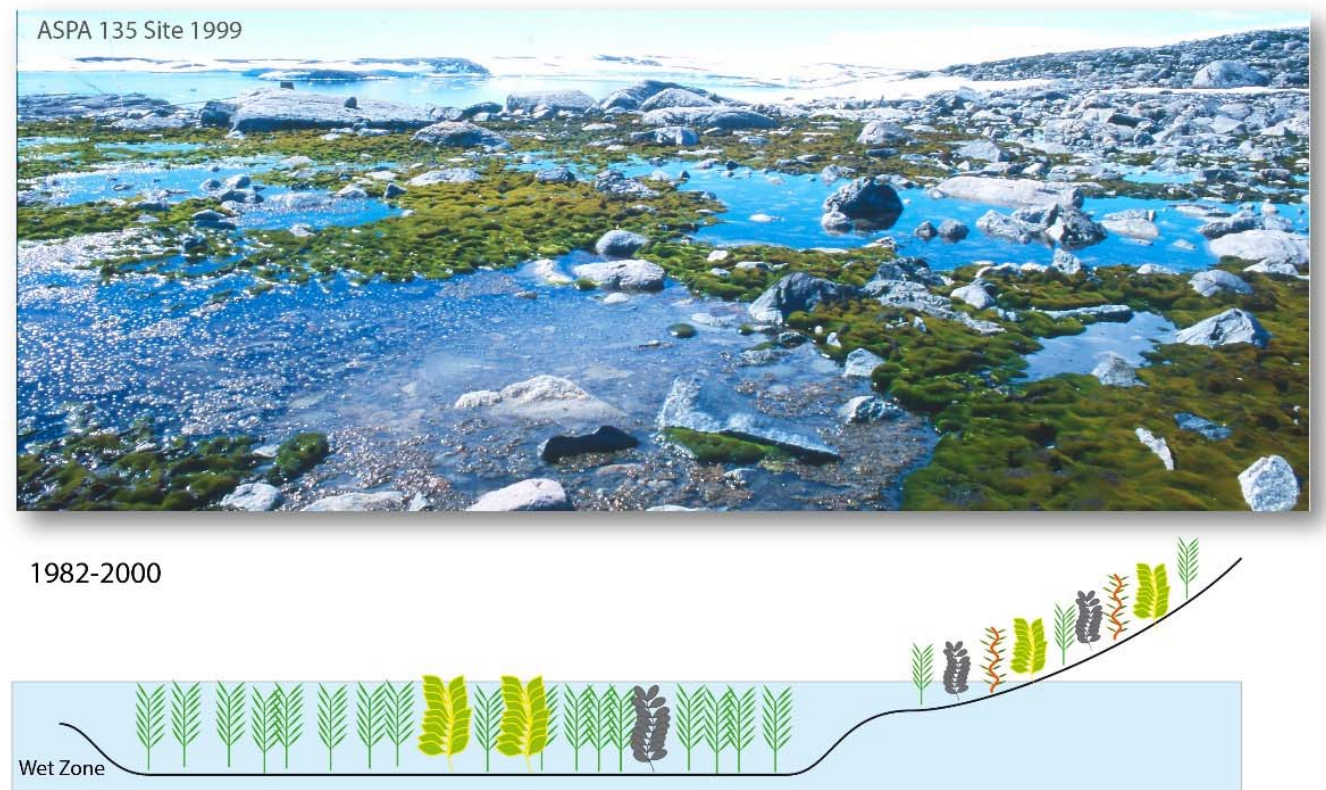

Moribund Moss

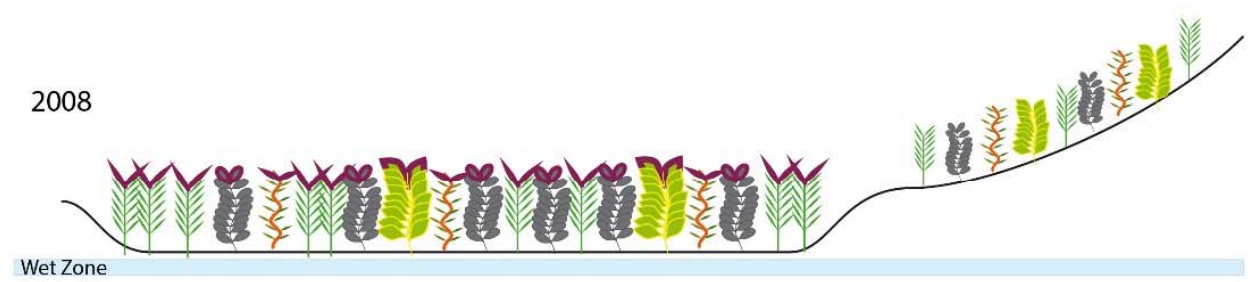

Wet Zone
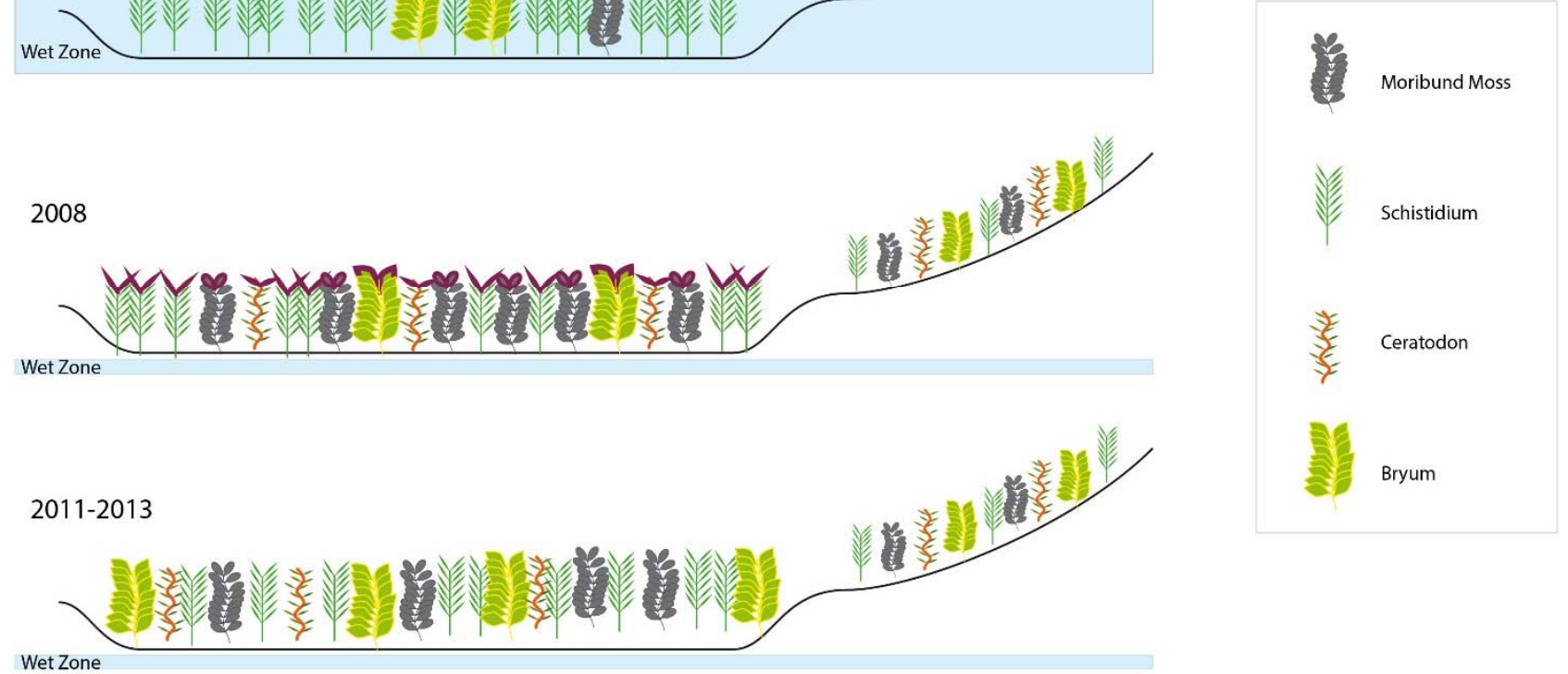

Figure 1 | Changes in East Antarctic moss communities (1982 and 2013). Periodic

flooding of moss beds (1982-2000) favoured Schistidium antarctici and Bryum pseudotriquetrum that tolerate submergence (Supplementary Table $\mathrm{S}^{24}$ ); however, Ceratodon purpureus, which does not survive extended submergence, was restricted to higher elevations. The APSA 135 site (photographed in 1999) illustrates inundation and since then the moss beds have dried and experience less submergence. Ceratodon purpureus can now survive and is more abundant, along with increased moribund moss (Fig. 2). Acute stress causes moss colour change (2008) due to more photoprotective (red-brown) pigments with some recent recovery (2013; Fig. 3). 

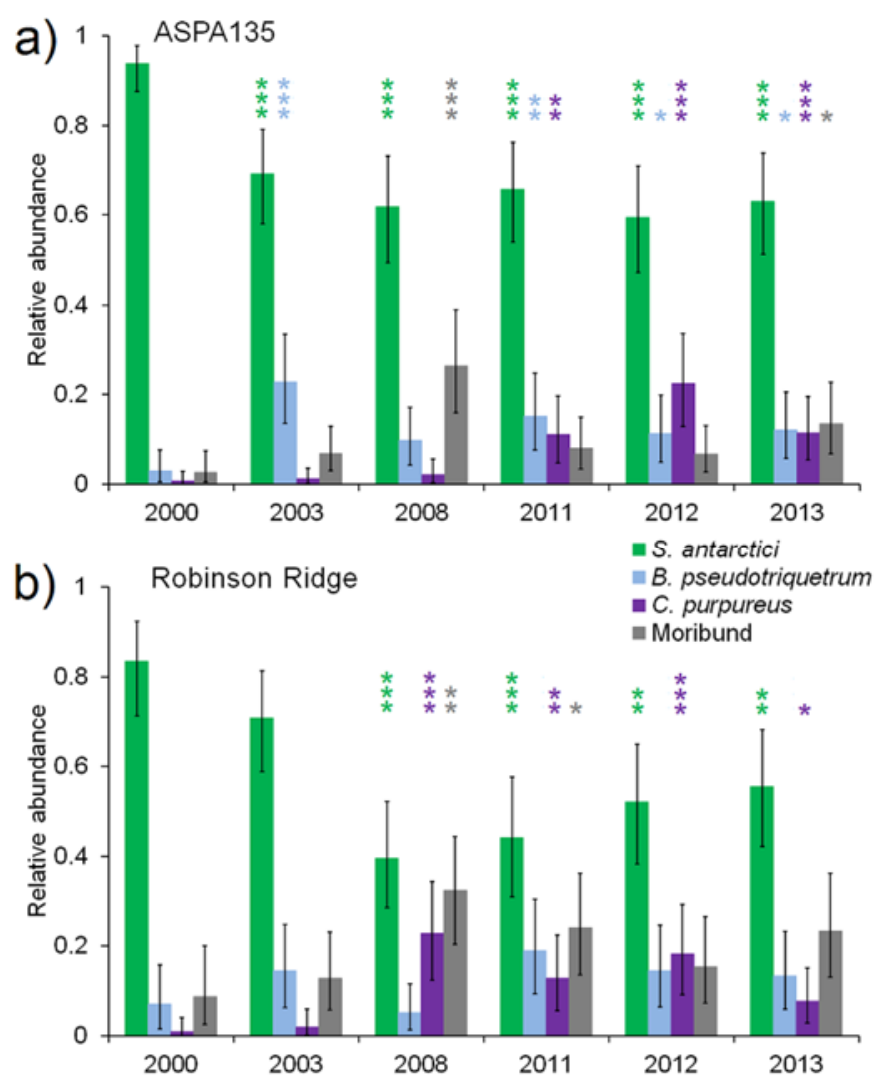

Figure 2 | Community composition at two sites (ASPA 135 and Robinson Ridge),

Windmill Islands, East Antarctica, sampled in six summer seasons between 2000 and 2013. The moss community consists of varying proportions of three species and unidentifiable moribund moss (lacking cell contents and essentially dead). Relative abundance $( \pm 95 \% \mathrm{CI})$ was estimated using a Bayesian model based on nine microsamples per quadrat ( $n=10$ quadrats in all years except 2000 where $n=7$; see Methods). The model also estimated the differences in relative abundance from the 2000 baseline year, with asterisks marking significant changes ( $* \mathrm{P}<0.05, * * \mathrm{P}<0.01, * * * \mathrm{P}<0.001)$. 

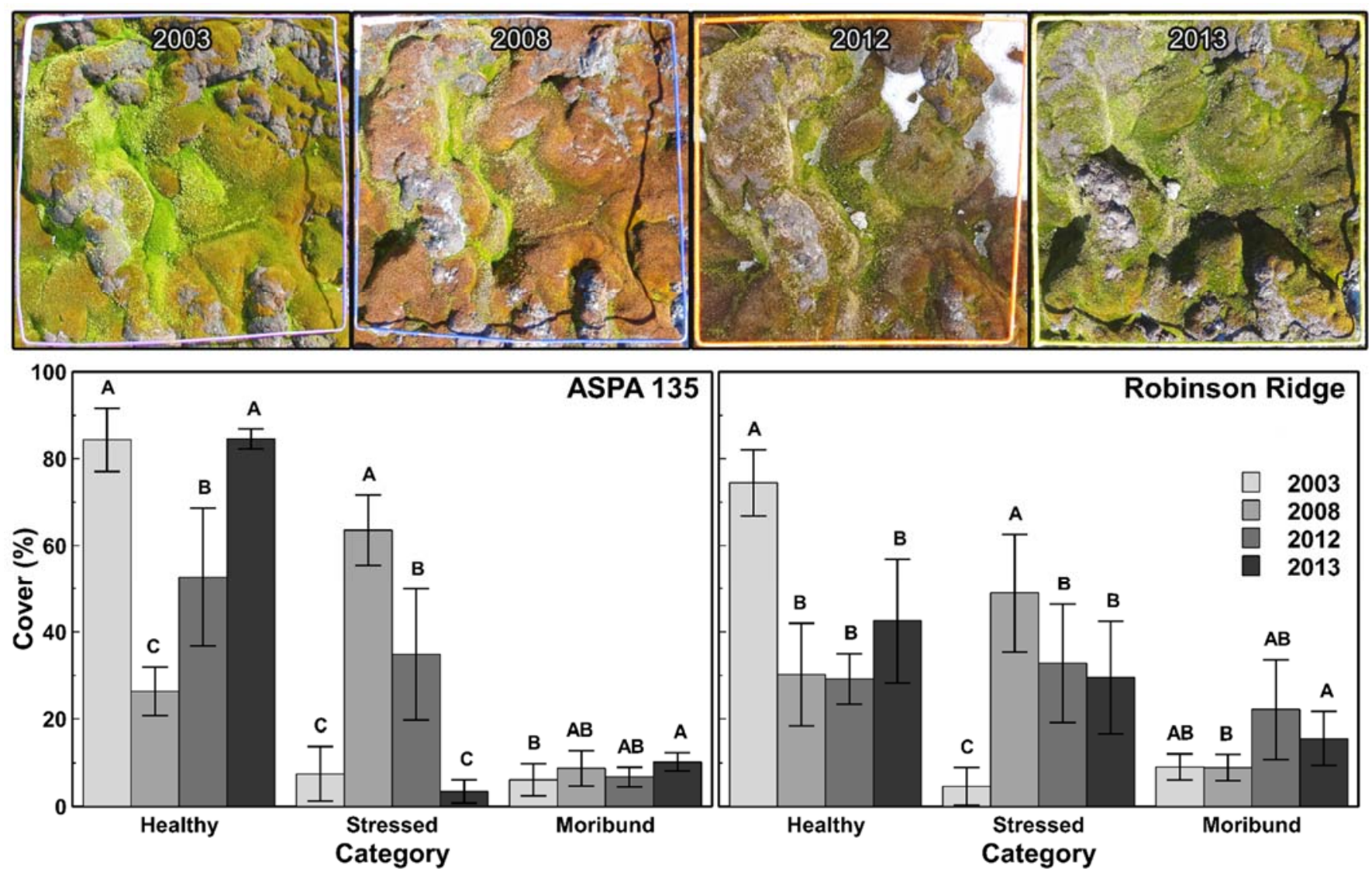

Figure 3 | Change in moss health between 2003 and 2013 at two East Antarctic sites.

Photographs demonstrate how moss health changed in a typical quadrat. Graphs show percent cover of three moss health categories (healthy, green; stressed, red-brown; moribund, greyblack). Data are mean percent cover $( \pm 95 \% \mathrm{CI} ; \mathrm{n}=10$ quadrats per site). Letters denote significant differences $(\mathrm{P}<0.05)$ within health categories. N.B. moss cover categories do not sum to $100 \%$, as quadrats contain small proportions of rock, snow, ice, water and lichens (data not shown), which did not change significantly throughout the decade at either site. 


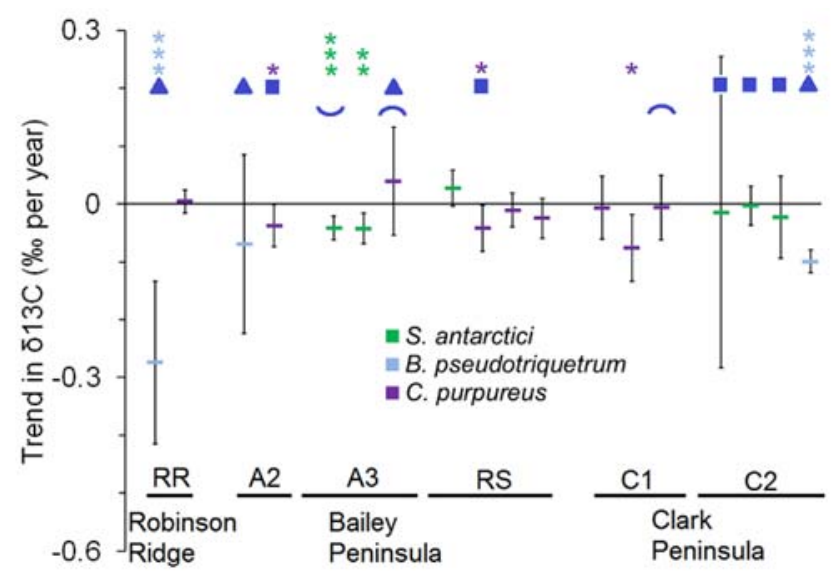

Figure 4 | Rate of change in moisture availability in East Antarctic mosses since 1960, estimated using isotopic analysis of 18 long moss shoot cores from six sites. Data represent linear trends in $\delta^{13} \mathrm{C}( \pm 95 \% \mathrm{CI})$. Negative $\delta^{13} \mathrm{C}$ change rates indicate that water availability has declined, with significant differences indicated by asterisks $(* \mathrm{P}<0.05 ; * * \mathrm{P}<0.01$, *** $\mathrm{P}<0.001)$. Squares indicate slow-growing cores with less than ten samples available since 1960. Triangles indicate fast-growing cores that span less than 20 years. Quadratic responses were also fitted, but only the three cores marked with blue curves were significantly nonlinear. 

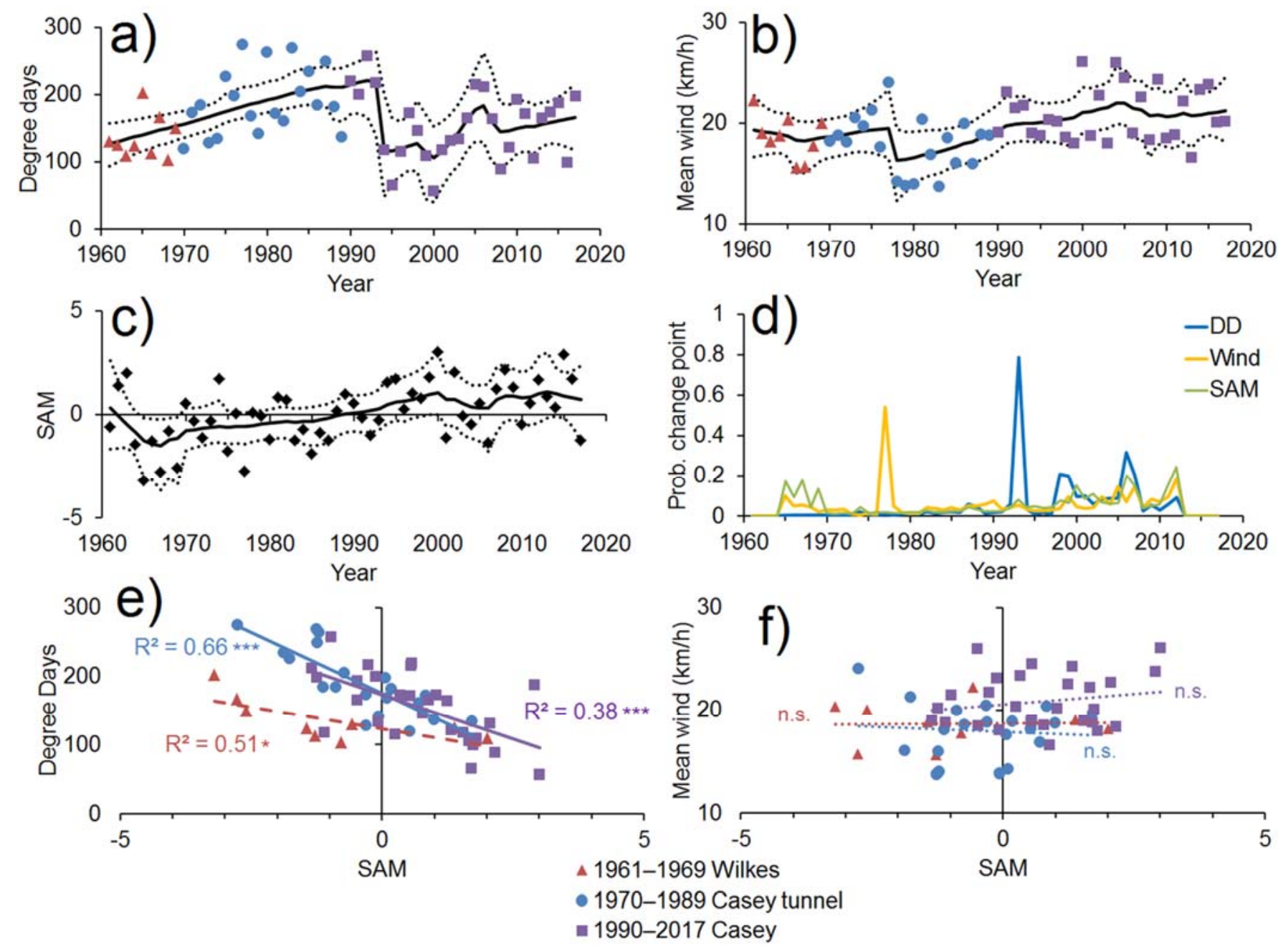

Figure 5 | Summer (Dec-Feb) Southern Annular Mode (SAM) and meteorological observations for the Windmill Islands since 1961. Trends in time series (a-c) and the probability of change points (d) were estimated by a Bayesian model (see Methods). Degree days (a, e), an indicator of snow melt, calculated as the sum of maximum temperatures for days when temperatures exceeded $0{ }^{\circ} \mathrm{C}$. Linear regressions $(\mathbf{e}, \mathbf{f})$ determined if SAM had significant relationships with meteorological variables, independent of location. Solid and dashed lines (e) indicate significant trends ( $* \mathrm{P}<0.05$; ** $\mathrm{P}<0.01, * * * \mathrm{P}<0.001)$, but the slope for Wilkes is different. Dotted lines were not significant (n.s.). 


\section{Methods}

We monitored vegetation change from 2003-2013 within 10 permanently marked quadrats at two sites in the Windmill Islands region, East Antarctica, and combined this with an earlier survey in 2000 of seven quadrats in the same locations ${ }^{24}$ (as detailed in Supplementary Fig. S1). Moss communities were targeted as the most sensible way to detect change in Antarctic continental vegetation. While mosses are the dominant plants in East Antarctica, lichens are the major component of vegetation at the study site. Lichens cope better with drier conditions but grow much more slowly ( 0.01 to $\left.0.07 \mathrm{~mm} \cdot \mathrm{yr}^{-1.20}\right)$. As a result, lichens would be less likely to demonstrate any measureable impacts from drying within 10 years and arguably by the time such changes were observed the moister moss communities could be irreparably damaged. We estimated the health status of the moss turf from digital photographs of each quadrat. Rate of change in moisture availability since 1960 was also measured using radiocarbon dating and $\delta^{13} \mathrm{C}$ analysis of 18 long intact moss shoot cores.

\section{Study area and species}

This study was conducted in the Windmill Islands of East Antarctica at six sites across three peninsulas (Supplementary Fig. S1). Three sites were on Bailey Peninsula: two in Antarctic Specially Protected Area 135 (ASPA; A2, 66.283 ${ }^{\circ} \mathrm{S}, 110.533^{\circ} \mathrm{E}^{32}$ and $\mathrm{A} 3,66.283^{\circ} \mathrm{S}$, $110.541^{\circ} \mathrm{E}$ ) and the third adjacent to the accommodation building at Casey Station, Red Shed (RS, $\left.66.368^{\circ} \mathrm{S}, 110.587^{\circ} \mathrm{E}^{33}\right)$. Two sites were in ASPA 136 on Clark Peninsula ${ }^{12}$, Clark 1 $\left(\mathrm{C} 1 ; 66.25^{\circ} \mathrm{S} 110.56^{\circ} \mathrm{E}\right)$ and Clark $2\left(\mathrm{C} 2 ; 66.25^{\circ} \mathrm{S} 110.56^{\circ} \mathrm{E}\right)$. The sixth site was at Robinson Ridge (RR; $66.368^{\circ} \mathrm{S}, 110.587^{\circ} \mathrm{E}^{33}$ ). These sites have all been described previously $\mathrm{y}^{12,32,33}$ except for the A3 site which is located along an ephemeral stream within ASPA 135. The A2 (Map ID 14450 http://data.aad.gov.au/aadc/mapcat/display_map.cfm?map_id=14450) and RR (Map ID 14451 http://data.aad.gov.au/aadc/mapcat/display_map.cfm?map_id=14451) 
sites are locations for permanent quadrats used for long-term monitoring of terrestrial vegetation dynamics in the Windmill Islands $\mathrm{s}^{34,35}$. Summer melt water in streams and lakes sustains some of the most extensive moss beds of continental Antarctica (e.g. Red Shed, ASPA135, Robinson Ridge and Clark $2 \operatorname{sites}^{36}$ ), comprised of three moss species: the dominant endemic moss Schistidium antarctici (Cardot) L.I. Savicz \& Smirnova, and two cosmopolitan species, Bryum pseudotriquetrum (Hedw.) Gaertn., Meyer \& Scherb., and Ceratodon purpureus (Hedw.) Brid. Ancient penguin guano deposits on these sites have contributed to high density of vegetation ${ }^{24,37}$.

Small, scattered populations of moss also exist in the more elevated areas e.g. Clark 1. Tolerance to desiccation and submergence varies between these three moss species (Supplementary Table S1). Schistidium antarctici typically grows in wetter sites and is least desiccation tolerant, whereas $C$. purpureus is not tolerant of submergence and is generally found in higher, drier areas, consistent with its high tolerance of desiccation (Fig. 1) ${ }^{21}$. In contrast, B. pseudotriquetrum is a relatively plastic species that is found in both dry and water-logged sites ${ }^{21,38}$. Bryum pseudotriquetrum tends to grow and respond faster under favourable conditions ${ }^{13,26,39}$, whereas C. purpureus and S. antarctici have similar slower growth and response times. Research and sample collection was conducted under the Antarctic Treaty (Environment Protection) Act 1980, Permit numbers ATEP2-12-13-4046, ATEP10-11-12-3042-3129, ATEP07-08-1313, ATEP05-06-2542 ATEP02-03, ATEP99/10 issued by the Commonwealth of Australia, Department of Environment to Sharon Robinson.

\section{Sample collection and analysis}

Quadrats $(25 \times 25 \mathrm{~cm})$ were located close to ephemeral summer water sources (Fig. 1), such as melt streams and lakes, which sustain verdant bryophyte communities, and positioned where bryophyte turf was dominant. Permanent quadrats were established in 2003 at the same 
locations as a pilot conducted in $2000^{24}$. These quadrats continue to be in some of the wettest locations in the region and to support the healthiest moss communities. The presence or absence of moss species was analysed from nine evenly distributed tweezer-pinch samples (referred to in main text as microsamples) taken from 7-10 quadrats at each site in 2000, 2003, 2008, 2011, 2012 and 2013 (details in Supplementary Table S2). We then scored presence of live and moribund moss within vegetation samples and identified live bryophytes to species $^{24}$.

Long intact moss shoot cores $(\mathrm{n}=18 ; 30-135 \mathrm{~mm})$ of $B$. pseudotriquetrum, $C$. purpureus and S. antarctici were also collected from six sites on Robinson Ridge (RR) and Bailey (RS, A2, A3) and Clark Peninsulas (C1, C2, Supplementary Fig. S1) between 2005 and 2013 during the austral summer season, and their ages were determined using radiocarbon dating (see below). As Antarctic moss turfs grow in a highly compact manner (approximately 20 shoots within $0.5 \mathrm{~mm}$ of one another ${ }^{21}$ ), samples were collected as a $1 \mathrm{~cm}^{2}$ 'core', with the assumption that shoot sections from within the core experience near identical growth conditions and would therefore be of a similar age ${ }^{12}$. Cores were extracted from the moss turf, air-dried to a constant mass at $60{ }^{\circ} \mathrm{C}$ and frozen at $-20{ }^{\circ} \mathrm{C}$ for transport back to Australia.

\section{Determination of relative abundance}

The relative abundance of each species in each quadrat and each year was modelled in $\mathrm{R}$ using the R2OpenBUGS Bayesian modelling package and similar methods introduced by Ashcroft et al. (2017) ${ }^{40}$ (see Fig2_Model.txt, Fig2_script.txt). The observed presence-absence data from the nine pinches in each quadrat were modelled using a binomial distribution with probability $\mathrm{P}_{\mathrm{y}, \mathrm{s}, \mathrm{q}}$ and number of samples $\mathrm{n}=9$. The probabilities were allowed to vary according to year (y), species (s) and quadrat (q) but were assumed to be non-linearly related to the cover of the respective species. The Bayesian model used Markov Chain Monte Carlo 
iteration to estimate the expected mean and $95 \%$ credible intervals for the relative abundances of the three species and moribund moss given the observed samples, with the relative abundances constrained to sum to $100 \%$. Note that $C$. purpureus was not detected prior to 2003 (see Fig. 1, Supplementary Table $\mathrm{S1}^{24,36,41}$ ) but the $95 \%$ credible interval still indicates the species could have been present but unobserved, hence the modelled abundance shows this species possibly occurring at low levels in 2000 (Fig. 2).

\section{Digital evaluation of moss health}

Quadrats were digitally photographed in all years except 2000 and 2011 (Supplementary Table S2). Digital red-green-blue (RGB) composite image analysis of the $25 \times 25 \mathrm{~cm}$ permanent vegetation monitoring quadrats were used to assess quadrat percent cover of moss that was categorised as healthy (green), stressed (red-brown) and moribund (grey-black; lacking pigments and photosynthetically inactive) moss. The physiological basis underlying this categorisation is that when moss resources are invested in photosynthesis and growth, plant tissues are high in chlorophyll content and appear green, whereas mosses under drought and/or light stress produce more protective pigments, including anthocyanins, flavonoids and carotenoids that give the plants a red or brown appearance $39,42,43$. These pigments play protective roles, including as sunscreens and antioxidants, which are especially important in high-radiation environments such as Antarctica. The extent to which the plants appear green or red depends on the relative proportions of these pigments in the cells and their cellular locations ${ }^{26,39}$. When mosses become moribund, their tips lose all pigment content and appear grey or black in colour. Although they may essentially be dead, if any viable cells remain they can regrow and, thus, these mosses are designated moribund.

The analysis was conducted using semi-automated object-based image analysis methods, based on RGB colour ratios. To estimate cover, the photos were first imported into the 
ArcGIS geographical information system (ESRI, Redlands, USA) for preprocessing. They were georeferenced to their corresponding GPS locations and consequently resized to the correct quadrat size of $25 \times 25 \mathrm{~cm}$. Masking digital polygons were manually delineated to define the extent of the quadrat and to mask out large rocks within each image. The preprocessed images and digital masks were then imported into the eCognition (Definiens Imaging GmbH, München, Germany) software package for object-based image analysis (OBIA) and classification. Optimal settings for image object segmentation were determined using the Estimation of Scale Parameter (ESP) tool ${ }^{44}$. Multiresolution image segmentation was performed using a scale parameter of 33 , with parameters of colour/shape set at $0.9 / 0.1$ and smoothness/compactness at $0.5 / 0.5$. The subsequent image classifier, which used a set of rules based on RGB (Red, Green, Blue) and HSI (Hue, Saturation, Intensity) digital value thresholds, was applied to separate moss turf within the quadrats into healthy, stressed and moribund moss categories. The eCognition OBIA classification of selected images was compared with a manual classification performed by the operator, resulting in an overall accuracy of $84 \%$. Average moss cover was $>94 \%$ and $>85 \%$ in the quadrats at ASPA 135 and Robinson Ridge, respectively, with a small proportion of other abiotic cover (i.e. rock, snow, ice or water) and lichens. Abiotic and lichen cover (total other categories: $1-6 \%$ at ASPA 135 and $12-16 \%$ at Robinson Ridge) did not change significantly for either site throughout the decade. For this reason, only the moss cover data (healthy, stressed and moribund) is presented in this paper (Fig. 3).

\section{Dating and stable carbon isotope analysis}

Mosses lay down sequential carbon signals reflecting the environmental conditions during growth ${ }^{13,45}$. Intact moss shoots can thus be accurately dated using 'bomb-peak' radiocarbon dating, where a peak in recent atmospheric radiocarbon occurred when large quantities of artificially-produced ${ }^{14} \mathrm{C}$ were injected into the atmosphere during the period of nuclear 
testing mostly in the late 1950 s and early $1960 \mathrm{~s}^{12,46}$. Data from four previously dated $C$. purpureus cores ${ }^{12}$ have also been included, which were remodelled to capture recent updates to atmospheric $\mathrm{CO}_{2}$ values ${ }^{47}$ as changes to atmospheric $\mathrm{CO}_{2}$ influence core $\delta^{13} \mathrm{C}$ through time $^{48}$.

Samples were identified to species by L. Clarke, S. Robinson, J. Bramley-Alves or M. Waterman. Cores were prepared for Accelerator Mass Spectrometry radiocarbon dating and $\delta^{13} \mathrm{C}_{\text {GRAPHITE }}$ (a part of the ${ }^{14} \mathrm{C}$ dating process used for fractionation correction) analysis at the Australian Nuclear Science and Technology Organisation as described by Clarke et al. $(2012)^{12}$. Each core was cut into 2 or $3 \mathrm{~mm}$ longitudinal segments using clean metal instruments to avoid carbon contamination. The moss samples were pre-treated in hot $2 \mathrm{M}$ $\mathrm{HCl}$ solution to remove possible carbonate contamination before being combusted to $\mathrm{CO}_{2}$ and then converted to graphite for accelerator mass spectrometry (AMS) ${ }^{14} \mathrm{C}$ analysis using the STAR Facility at the Australian Nuclear Science and Technology Organisation, Australia (ANSTO; $\left.{ }^{12}\right)$. A small portion of the graphite was used for stable isotopic carbon $\left(\delta^{13} \mathrm{C}\right)$ determination to correct for isotopic fractionation of ${ }^{14} \mathrm{C}$ using an elemental analyser/isotoperatio mass spectrometer. In order to obtain accurate calendar ages for the consecutive moss segments of a particular core, their obtained ${ }^{14} \mathrm{C}$ content, referred to as percent modern carbon (pMC), were modelled using a Bayesian analysis approach - "Simple Sequence" deposition model of the OxCal v4.2 program $^{49}$.

This approach calibrates their ages against our constructed atmospheric ${ }^{14} \mathrm{C}$ curves and models the moss ages based on the assumption that subsequent moss segments within one core grew in a chronological manner. The constructed atmospheric ${ }^{14} \mathrm{C}$ curves consist of Southern Hemisphere summer ${ }^{14} \mathrm{C}$ data for the pre-bomb $\left(\mathrm{SHCal13}{ }^{50}\right)$ and post-bomb $(\mathrm{SH}$ zone $1-2^{51}$ ) extended beyond 2011 by exponential extrapolation. Each moss sample might span more than a year of growth as indicated by the fact that the maximum pMC values for 
each long shoot core were lower than the annual bomb-peak value of the SH zone 1-2 data of $\sim 166 \mathrm{pMC}^{51}$. This time integration of moss samples was therefore taken into account when building the constructed atmospheric ${ }^{14} \mathrm{C}$ curves $\left(\right.$ see $\left.^{12}\right)$. The data set of modern ${ }^{14} \mathrm{C}$ ages of the moss cores depicted in Fig. 4 is included as Supplementary Fig. S2.

In addition to recording their age in their cells as described above, mosses have the potential to record past bioavailable water climates via assimilation of stable carbon isotopes $\left({ }^{12} \mathrm{C}\right.$ and ${ }^{13} \mathrm{C}$ ) from the atmosphere. The enzyme RuBisCO favours the fixation of lighter ${ }^{12} \mathrm{CO}_{2}$ during photosynthesis $^{52-55}$. Due to their lack of stomata there is no diffusional limitation imposed by stomatal control and so mosses fix more diffused ${ }^{12} \mathrm{CO}_{2}$ than ${ }^{13} \mathrm{CO}_{2}$ into sugars and cellulose when the leaf surface is dry. In wetter environments when the moss surface is submerged in a layer of water (see Fig. 1), RuBisCO becomes $\mathrm{CO}_{2}$-limited and discriminates less against ${ }^{13} \mathrm{CO}_{2}$, thus, more of the heavier stable carbon isotope is incorporated as ${ }^{13} \mathrm{C}_{\text {CELlulose }}{ }^{54}$. The change $(\delta)$ in the ratio between fixed carbon-12 and carbon-13 $\left(\delta^{13} \mathrm{C}_{\text {CELLULOSE }}\right)$ indicates the water environment (dry/wet) and correlates to the measured $\delta^{13} \mathrm{C}_{\text {GRAPHITE }}$ required for AMS ${ }^{14} \mathrm{C}$ correction (above; see Bramley-Alves et al. $2015^{13}$ for more information). Correction of this moss shoot $\delta^{13} \mathrm{C}_{\text {GRAPHITE }}$ for temporal changes in atmospheric $\delta^{13} \mathrm{C}$ due to fossil fuel emissions was undertaken according to Clarke et al. $(2012)^{12}$.

To determine the trends in immediate water environment for each moss core, the rate of change in $\delta^{13} \mathrm{C}_{\text {GRAPHITE }}$ per year of dated intact moss shoot core sections was obtained using linear regression analysis on all data since 1960. The resultant slopes of these regressions are graphed in Fig. 4. We restricted our analysis to dates after 1960 to focus on recent changes and because dates prior to the bomb-peak could not be estimated as accurately. 


\section{Analysis of local and global climate trends}

Meteorology data, including daily minimum and maximum temperatures, precipitation and average and maximum wind speed, were obtained from the Bureau of Meteorology for Casey (station 300017, 1990-2017) with earlier observations from the nearby Wilkes (station 300003, 1961-1969) and Casey (Tunnel) stations (station 300006, 1970-1989;

Supplementary Fig. S1). Data for the Southern Annular Mode (SAM) ${ }^{15,17}$ were obtained from the British Antarctic Survey. The data for each year were taken as the average for the austral summer (December of preceding year through January and February). As long-term meteorological trends can be confounded by both documented and undocumented changes in equipment, land use and location ${ }^{56}$, we modelled the time series using four linear segments, with three change points to cater for potential discontinuities. Each linear segment had to be at least five years long, to avoid overfitting to individual years, and could vary in both slope and intercept. The years for the change points could change in each iteration. Uninformed priors were used. When averaged over 20000 iterations this produced a 95\% CI for the overall climate trend as well as the probability that a change point occurred in each year ${ }^{57}$. As the change points were not always in the same years, the mean lines were a non-linear fit to the data. Correlations between regional meteorological and continent-wide SAM data were analysed conservatively by station location, in case local changes in instrument location affected records. None of the time series had high probabilities of discontinuities at the same time as station moves $(1969,1989)$ and so we assumed shifts represented actual shifts in climate rather than station biases.

While results are only presented for degree days and mean wind speeds, minimum and maximum temperatures exhibit similar trends to degree days and maximum wind speeds to mean wind speeds. Precipitation could not be analysed as there are problems recording snow due to the strong winds and frequent occurrences of blown snow. 
We analysed and present the correlations between SAM and degree days / mean wind speeds as one factor that is potentially driving the drying trend (Fig. 5). We acknowledge that these correlations with SAM do not prove causation, but there is prior literature that supports SAM leading to increased wind speeds and cooler maximum temperatures ${ }^{1,3,16,17}$. We also examined correlations between meteorological observations and ozone observations, zonal wave 3 (ZW3) and its Australian Zone variant (AZ3), but results are not presented as trends were weaker, these factors were not as well supported by prior literature, and we preferred to test a priori hypotheses rather than examine post-hoc correlations.

\section{Availability of data sets}

Data sets are publicly available from the Australian Antarctic Data Centre (AADC) at http://dx.doi.org/doi:10.4225/15/59c999a4c2145.

\section{References}

32 Dunn, J. L. \& Robinson, S. A. Ultraviolet B screening potential is higher in two cosmopolitan moss species than in a co-occurring Antarctic endemic moss: Implications of continuing ozone depletion. Glob. Change Biol. 12, 2282-2296 (2006).

33 Lovelock, C. E. \& Robinson, S. A. Surface reflectance properties of Antarctic moss and their relationship to plant species, pigment composition and photosynthetic function. Plant Cell Environ. 25, 1239-1250 (2002).

34 Robinson, S. A., Wasley, J. \& King, D. Indicator 72 - Windmill Islands terrestrial vegetation dynamics, $<$ http://data.aad.gov.au/aadc/soe/display_indicator.cfm?soe_id=72> (2009).

35 State of the Environment 2011 Committee. Australia State of the Environment 2011. Independent report to the Australian Government Minister for Sustainability, Environment, Water, Population and Communities. 477-565 (Canberra, 2011).

36 Lewis Smith, R. I. Plant community dynamics in Wilkes Land, Antarctica in Proc. NIPR Symp. Polar Biol. 229-244 (1990). 
37 Emslie, S. D. \& Woehler, E. J. A 9000-year record of Adélie penguin occupation and diet in the Windmill Islands, East Antarctica. Antarct. Sci. 17, 57-66 (2005).

38 Robinson, S. A., Wasley, J., Popp, M. \& Lovelock, C. E. Desiccation tolerance of three moss species from continental Antarctica. Funct. Plant Biol. 27, 379-388 (2000).

39 Waterman, M., Bramley-Alves, J., Miller, R., Keller, P. \& Robinson, S. Antarctic mosses enhance red cell wall photoprotection under stress. Biol. Res. (in review).

40 Ashcroft, M. B. et al. Moving beyond presence and absence when examining changes in species distributions. Glob. Change Biol. 23, 2929-2940 (2017).

41 Selkirk, P. M. \& Seppelt, R. D. Species distribution within a moss bed in Greater Antarctica. Symp. Biol. Hungarica 35, 279-284 (1987).

42 Post, A. Photoprotective pigment as an adaptive strategy in the Antarctic moss Ceratodon purpureus. Polar Biol. 10, 241-245 (1990).

43 Waterman, M. J. et al. Antarctic Moss Biflavonoids Show High Antioxidant and Ultraviolet-Screening Activity. J. Nat. Prod. 80, 2224-2231 (2017).

44 Drăguţ, L., Tiede, D. \& Levick, S. R. ESP: a tool to estimate scale parameter for multiresolution image segmentation of remotely sensed data. Int. J. Geogr. Inf. Sci. 24, 859-871 (2010).

45 Royles, J. et al. Plants and soil microbes respond to recent warming on the Antarctic Peninsula. Curr. Biol. 23, 1702-1706 (2013).

46 Hua, Q. Radiocarbon: A chronological tool for the recent past. Quat. Geochrono. 4, 378-390 (2009).

47 Rubino, M. et al. A revised 1000 year atmospheric $\delta^{13} \mathrm{C}-\mathrm{CO}_{2}$ record from Law Dome and South Pole, Antarctica. J. Geophys. Res.-Atmos. 118, 8482-8499 (2013).

48 Dan, Y. The paper trail of the ${ }^{13} \mathrm{C}$ of atmospheric $\mathrm{CO}_{2}$ since the industrial revolution period. Environ. Res. Lett. 6, 034007 (2011).

49 Bronk Ramsey, C. Bayesian analysis of radiocarbon dates. Radiocarbon 51, 337-360 (2009).

50 Hogg, A. G. et al. SHCal13 Southern Hemisphere calibration, 0-50,000 years cal BP. Radiocarbon 55, 1889-1903 (2013).

51 Hua, Q., Barbetti, M. \& Rakowski, A. Z. Atmospheric radiocarbon for the period 1950-2010. Radiocarbon 55, 2059-2072 (2013). 
52 Williams, T. \& Flanagan, L. Effect of changes in water content on photosynthesis, transpiration and discrimination against ${ }^{13} \mathrm{CO}_{2}$ and $\mathrm{C}^{18} \mathrm{O}^{16} \mathrm{O}$ in Pleurozium and Sphagnum. Oecol. 108, 38-46 (1996).

53 Rice, S. Variation in carbon isotope discrimination within and among Sphagnum species in a temperate wetland. Oecol. 123, 1-8 (2000).

54 Rice, S. K. \& Giles, L. The influence of water content and leaf anatomy on carbon isotope discrimination and photosynthesis in Sphagnum. Plant Cell Environ. 19, 118124 (1996).

55 Farquhar, G., Ehleringer, J. \& Hubick, K. Carbon isotope discrimination and photosynthesis. Annu. Rev. Plant Physiol. Plant Mol. Biol. 40, 503-537 (1989).

56 Ducré-Robitaille, J.-F., Vincent, L. A. \& Boulet, G. Comparison of techniques for detection of discontinuities in temperature series. Int. J. Climatol. 23, 1087-1101 (2003).

57 Ruggieri, E. A Bayesian approach to detecting change points in climatic records. Int. J. Climatol. 33, 520-528 (2013). 